\title{
Reduction of Covalently Closed Circular DNA with Long-term Nucleos(t)ide Analogue Treatment in Chronic Hepatitis B
}

Ching-Lung Lai*, ${ }^{1,2}$ Danny Wong*, ${ }^{1,2}$ Philip Ip, ${ }^{3}$ Malgorzata Kopaniszen, ${ }^{1}$ Wai-Kay Seto, ${ }^{1,2}$ James Fung, ${ }^{1,2}$ Fung-Yu Huang, ${ }^{1}$ Brian Lee, ${ }^{4}$ Giuseppe Cullaro, ${ }^{5}$ Chun Kong Chong, ${ }^{1}$ Ringo Wu, ${ }^{1}$ Charles Cheng, ${ }^{1}$ John Yuen, ${ }^{1}$ Vincent Ngai, ${ }^{1}$ Man-Fung Yuen ${ }^{1,2}$

${ }^{1}$ Department of Medicine, The University of Hong Kong, Hong Kong

${ }^{2}$ State Key Laboratory for Liver Research, The University of Hong Kong, Hong Kong

${ }^{3}$ Department of Pathology, The University of Hong Kong, Hong Kong

${ }^{4}$ Johns Hopkins University School of Medicine, Maryland, USA

${ }^{5}$ Department of Medicine, Columbia University Medical Campus, New York City, NY, USA *co-first and corresponding authors

Correspondence: Prof. Ching-Lung Lai and Dr. Danny Wong, Department of Medicine, The University of Hong Kong, Queen Mary Hospital, Hong Kong, China.

Tel: (852) 22554252; $22553070 \quad$ Fax: (852) 28162863; 22554901

E-mail: hrmelcl.hku.hk; dannykhwong@gmail.com

Keywords: hepatitis B; liver biopsy; antiviral therapy

Abbreviations: HBV, hepatitis B virus; PCR, polymerase chain reaction; cccDNA, covalently closed circular DNA; rcDNA, relaxed circular DNA; DHBV, duck HBV; ihHBV DNA, total intrahepatic HBV DNA; pgRNA, pregenomic RNA; HBsAg, hepatitis B surface antigen; $\mathrm{HBcAg}$, hepatitis $\mathrm{B}$ core antigen; $\mathrm{HBeAg}$, hepatitis $\mathrm{B}$ e antigen; anti-HBe, antibody against HBeAg; ALT, alanine aminotransferase; ULN, upper limit of normal; HBcrAg, hepatitis B core-related antigen 
Electronic word count of the manuscript (including abstract, references, tables and figure legends): 6000 words

Number of figures and tables: 4 figures and 3 tables

Conflict of interest statement: Ching-Lung Lai has given sponsored lectures and is an advisory board member of Gilead Sciences and Abbvie, and holds shares of Gilead Sciences. Danny Wong has received travel support from Gilead Sciences and Abbvie. Man-Fung Yuen has given sponsored lectures and received research funding and is an advisory board member of Bristol-Myers Squibb, Novartis, Gilead Sciences, and Roche Diagnostics. Wai-Kay Seto is an advisory board member of Gilead Sciences and Bristol-Myers Squibb and has given sponsored lectures for Gilead Sciences, Bristol-Myers Squibb and Novartis. James Fung has given sponsored lectures for Bristol-Myers Squibb and research funding from Novartis. Fung-Yu Huang and Chun Kong Chong have received travel support from Gilead Sciences. The remaining authors have no conflict of interest.

Financial support statement: This study is supported by the Lichi Charitable Foundation.

\section{Authors contributions:}

Study concept and design: Ching-Lung Lai Acquisition, analysis, or interpretation of data: Danny Wong, Philip Ip, Malgorzata Kopaniszen, Fung-Yu Huang, Brian Lee, Giuseppe Cullaro, Chun Kong Chong Drafting of the manuscript: Ching-Lung Lai, Danny Wong Critical revision of the manuscript for important intellectual content: Man-Fung Yuen, WaiKay Seto, Brian Lee, Giuseppe Cullaro

Statistical analysis: Danny Wong, Wai-Kay Seto, James Fung

Obtained funding: Ching-Lung Lai 


\begin{abstract}
Background and aims: Hepatitis B virus (HBV) covalently closed circular DNA (cccDNA), a minichromosome essential for HBV replication, is supposed to be resistant to nucleos(t)ide analogue treatment. We investigated the effect of long-term nucleos(t)ide analogue treatment on cccDNA.
\end{abstract}

Methods: Among 129 patients who had been enrolled in previous international nucleos(t)ide analogue clinical trials and had liver biopsies at baseline and one year after treatment, we recruited 43 patients on long-term continuous treatment for 72 to 145 months for a third liver biopsy. Serum HBV DNA, hepatitis B surface antigen (HBsAg) levels, total intrahepatic HBV DNA (ihHBV DNA), cccDNA, HBV pregenomic RNA (pgRNA) as well as histologic changes were examined.

Results: At the time of the third biopsy, serum HBV DNA levels were undetectable in all but one patient. The median levels of HBsAg, ihHBV DNA, and cccDNA were $2.88 \log \mathrm{IU} / \mathrm{mL}$, 0.03 copies/cell, and 0.01 copies/cell, respectively. Compared to baseline levels, there was reduction of HBsAg levels by $0.54 \log (71.46 \%)$, ihHBV DNA levels by $2.81 \log (99.84 \%)$, and cccDNA levels by $2.94 \log (99.89 \%)$, with $49 \%$ having cccDNA levels below the detection limit. One patient had undetectable HBsAg. The median pgRNA level, measured only in the third biopsy, was 0.021 copies/cell, with $40 \%$ of patients having undetectable pgRNA.

Conclusions: Long-term nucleos(t)ide analogue treatment induced marked depletion of cccDNA in the majority of patients while serum HBsAg levels, though reduced, were detectable in all but one patient. Whether cccDNA depletion is sustained and associated with better patient outcome requires further study.

\title{
Abstract word count: 250
}




\section{LAY SUMMARY}

It is generally presumed that a form of hepatitis B virus DNA, called covalently closed circular DNA (cccDNA), which hides inside the nuclei of liver cells of patients with chronic hepatitis B, cannot be reduced by antiviral treatment. The present study showed that with prolonged treatment (median period 126 months), cccDNA can be markedly reduced, with $49 \%$ of liver biopsies having undetectable cccDNA. This suggests that viral replication capacity would be very low after prolonged antiviral treatment. 


\section{INTRODUCTION}

Globally, chronic hepatitis B affects approximately 240 million people and contributes to more than 780,000 deaths annually [1]. Long-term nucleos(t)ide analogue treatment has been shown to be effective in suppression of the hepatitis B virus (HBV) replication to levels below the detection limits of polymerase chain reaction (PCR) assays, in histologic improvement (including reversal of cirrhosis), and in reducing the incidence of hepatocellular carcinoma [2-4]. Its long-term effect on intrahepatic covalently closed circular DNA (cccDNA) is less well documented.

HBV is a partially double-stranded DNA virus which exists in the serum in relaxed circular DNA (rcDNA) form. Following binding to hepatocytes, the rcDNA viral genome is transported to the nucleus where the incomplete strands of HBV DNA are completed. The viral DNA becomes associated with cellular and viral proteins, and supercoiled into a cccDNA conformation.

cccDNA is the template for transcription of HBV RNA, which is the first step of HBV replication. It resembles a mini-chromosome, is highly stable and resistant to nucleos(t)ide analogues which inhibit reverse transcription. In duck HBV (DHBV) studies, the half-life of DHBV cccDNA has been estimated to be 35 to 57 days [5]. The pool of cccDNA is maintained, and may be amplified, through transport of newly formed DNA precursors in the hepatocyte cytoplasm back into the nucleus. The persistence of cccDNA is a well-known obstacle to the cure of chronic hepatitis B [6,7]. However it has been postulated that cccDNA may be depleted through natural cell division and cell death with nucleos(t)ide treatment, but this has not been proven [8]. It has also been shown that while cccDNA may decrease during treatment, integrated viral DNA shows no discernible decrease [9]. But whether pre-existing integrated HBV DNA plays a role in hepatocarcinogenesis even when no new integration occurs with effective suppression of viral replication is uncertain. 
Our Liver Center and other centers have demonstrated that one year of nucleos(t)ide analogue treatment can reduce intrahepatic HBV DNA and cccDNA [10-14]. Because of the requirement for serial liver biopsies, the effect of long-term nucleos(t)ide analogue treatment on cccDNA has seldom been investigated. The primary aim of the present study is to determine the degree of reduction of cccDNA as well as total intrahepatic HBV DNA (ihHBV DNA) and pregenomic RNA (pgRNA) in liver biopsies of patients who had been receiving continuous nucleos(t)ide treatment for up to 12 years. We also documented the histologic changes in the liver biopsies, including semi-quantitative changes in the hepatitis B surface antigen ( $\mathrm{HBs} \mathrm{Ag})$ and core antigen $(\mathrm{HBcAg})$ by immunohistochemical staining. 


\section{METHODS}

\section{Patients and samples}

This is a prospective study. Eligible patients included all HBsAg-positive patients recruited in clinical trials after 2002, with a baseline liver biopsy and a biopsy after one year of therapy according to the trial protocols for entecavir vs. lamivudine $[15,16]$, telbivudine vs. lamivudine [17], and clevudine vs. adefovir. The last trial was prematurely terminated with all patients either switched to or maintained on adefovir. For inclusion in the present study, all patients are required to be on continuous nucleos(t)ide analogue treatment with continued viral suppression for over five years. Patients who had rebound of HBV DNA $\geq 1 \log _{10} \mathrm{IU} / \mathrm{mL}$ or who developed resistance as tested by the INNO-LiPA DR v3 Assay (Innogenetics, Ghent, Belgium) were given additional, or were switched to, appropriate nucleos(t)ide analogues for continued viral suppression. None of the patients had co-infection with hepatitis $\mathrm{C}$, hepatitis D, or human immunodeficiency virus, or the presence of other forms of liver disease.

The patients were invited to participate in the present study for a third liver biopsy. Throughout the period of follow-up, patients had liver function tests, HBV DNA, hepatitis B e antigen ( $\mathrm{HBeAg}) /$ antibody against $\mathrm{HBeAg}($ anti-HBe) monitored every three to six months. All liver biopsies were either snap-frozen in liquid nitrogen or preserved in Allprotect Tissue Reagent (Qiagen, Hilden, Germany), followed by storage at $-80^{\circ} \mathrm{C}$ until analysis.

This study had been approved by the Institutional Review Board of the University of Hong Kong and Hospital Authority, Hong Kong West Cluster. Written informed consent was obtained from all patients for participating in the study and a separate consent for the liver biopsies.

\section{Analytical Tests}


Serum HBV DNA was measured by the COBAS TaqMan HBV Test (Roche Diagnostics, Branchburg, NJ), with a lower limit of detection of $20 \mathrm{IU} / \mathrm{mL}$.

ihHBV DNA, cccDNA, and pgRNA were assayed by real-time PCR or real-time reverse transcription (RT)-PCR, as previously described [12,18,19]. Intrahepatic DNA were extracted from approximately $5 \mathrm{mg}$ of liver biopsies using either the QIAamp DNA Mini Kit or the Allprep DNA/RNA/Protein Mini Kit (both from Qiagen). According to the manufacturer, both the QIAamp Mini kit and the Allprep Mini Kit had similar performance in terms of DNA extraction. Intrahepatic RNA were extracted using the Allprep DNA/RNA/Protein Mini Kit.

The extracted DNA was subjected to real-time PCR quantification of ihHBV DNA and cccDNA using the QuantiFast Probe PCR kit in a RotorGene Q real-time PCR system (both Qiagen). To minimize variations in PCR quantification of the baseline, year 1, and third liver biopsy samples of the present study, identical real-time PCR conditions were used. Briefly, specific primers and fluorescence resonance energy transfer (FRET) probes targeting the $\mathrm{S}$ regions were used for ihHBV DNA detection, while those targeting the nicked region of the HBV DNA genome were used for cccDNA detection. Sequences of the primers and probes used have been described previously [12]. For cccDNA detection, the DNA samples were first pre-treated with Plasmid-Safe DNase (Epicenter, Madison, WI). Real-time PCR reaction was set up with the same PCR conditions as in ihHBV DNA detection. Serial diluted samples of known concentrations of a cloned HBV plasmid were included as the quantitation standards. The specificity and reproducibility of the cccDNA detection assay was confirmed using nuclear extracted DNA from cultured HepG.2.2.15 cells and archived biopsy-extracted DNA (Supplementary Tables 1 and 2 and Supplementary Figure 1).

Specific primers and probes targeting to the precore regions at the start of pgRNA transcript were used for pgRNA detection $[18,19]$, using the QuantiFast Probe RT-PCR Kit 
(Qiagen). RT-PCR amplification of liver RNA was set up in the same PCR conditions as in ihHBV DNA detection, except that an isothermal step of complementary DNA (cDNA) synthesis was included before PCR amplification. Although the original primers and probes for real-time quantification of $\mathrm{HBV}$ DNA and RNA were evaluated in patients with genotypes A and D, only single base differences from reference genotype B and C sequences (the predominant genotypes in our locality) were found.

The number of cells in the liver tissues were determined by quantification of human genomic DNA by the Light-Cycler Control DNA kit (Roche Diagnostics), using the $\beta$-globin gene as the house-keeping gene. Since intrahepatic DNA and RNA were simultaneously extracted from the same piece of liver tissue using the Allprep extraction kit, the amount of HBV DNA and RNA can be normalized against the cellular DNA content from the same piece of tissue. In the present study, we re-defined the lower limits of detection of the quantitative real-time PCR by Probit analysis using cloned HBV plasmids of known concentrations spiked with HepG2 hepatoma cells and taking into account the nucleic acid extraction process (Supplementary Figure 2). The lower limits of detection of ihHBV DNA, cccDNA, and pgRNA measurements were determined to be $0.001,0.005$, and 0.001 copies/cell, respectively.

\section{Histologic analysis}

Liver biopsies for histologic examination were fixed in $10 \%$ buffered formalin and embedded in paraffin. Slides of $4 \mu \mathrm{m}$ thick were stained with hematoxylin and eosin, and at least 1 deeper section of each biopsy was examined. Masson trichrome stain was performed for more accurate assessment of fibrosis. Histologic grading and staging were assessed by pathologists who were blinded to the patient identities and drug treatment. Assessment was made according to the modified Knodell scoring system [20]. Assessment of non-alcoholic 
steatohepatitis was based on the system described by Kleiner et al [21]. Immunohistochemical staining was performed using antibodies against HBsAg (S1-210; Covance. Emeryville, CA) and HBcAg (RB-1413-R7; Thermo Scientific, Fremont, CA). The percentage of positive staining was estimated by counting the number of positive cells against the background of unstained hepatocytes.

\section{Statistical analysis}

All statistical analyses were performed by using SPSS 18.0 (SPSS Inc, Chicago, IL). The Mann-Whitney $\mathrm{U}$ test was used to test continuous variables with skewed distribution. Related samples were tested with the paired sample t-test or the Wilcoxon Sign Ranks Test as appropriate. Categorical variables were tested with the Chi-square test. Correlation between two variables was tested using Pearson correlation analysis following logarithmic transformation of the skewed data. Statistical significance was defined by a $p$ value of less than 0.05 . 


\section{RESULTS}

\section{Baseline characteristics and serological findings}

There were a total of 129 patients who participated in the three clinical trials: entecavir $(n=20)$ versus lamivudine $(n=18)$; telbivudine $(n=36)$ versus lamivudine $(n=31)$, and clevudine $(n=16)$ versus adefovir $(n=8)$. The allocation of the 129 patients is shown in Figure 1. The effects of one year of nucleos(t)ide analogue treatment in 124 of these patients have been previously reported [11]. Eighty-five patients were eligible for the present study according to the recruitment criteria. All were contacted; 43 patients consented to join the study and to have a third biopsy. Twenty-eight of these 43 patients were males, 15 females, with a median age (range) of 43 (24 to 63) years. Eleven patients had HBV genotype B and 32 had HBV genotype C. At baseline, 23 patients were positive for $\mathrm{HBeAg}$ and 20 for antiHBe. At the time of the third biopsy, four remained positive for $\mathrm{HBeAg}$, nine were negative for both $\mathrm{HBeAg}$ and anti-HBe, and 29 were positive for anti-HBe. One patient, positive for anti-HBe at baseline, lost HBsAg after 68 months of treatment. The median duration of treatment with nucleos(t)ide analogues was 126 months (range 72 to 145 months). A brief summary of their drug history is shown in Table 1.

\section{Histology findings}

The mean $( \pm \mathrm{SD})$ Knodell scores of the baseline biopsy, year 1 biopsy, and the third biopsy were $3.88( \pm 2.68), 1.26( \pm 1.24), 1.35( \pm 1.63)$ respectively (Figure $2 \mathrm{~A})$. Compared to the baseline biopsy, the year 1 biopsy and the third biopsy showed significant reduction in score $(\mathrm{p}<0.0001$ for both), whereas there was no difference in the scores between the year 1 biopsy and the third biopsy $(\mathrm{p}=0.759)$. The changes in Ishak Fibrosis score are shown in Figure 2B. None of the 43 patients had an Ishak score of above four at baseline. 
Immunohistochemical staining of the third liver biopsy for HBsAg showed that 12 patients (27.9\% of the 43 patients) had 0 to $1 \%$ cells, $23(53.3 \%)$ had 5 to $10 \%$ cells, 5 patients (11.6\%) had 20 to $30 \%$ cells staining positive, and only one patient each had $50 \%$, $80 \%$ and $100 \%$ cells staining positive for HBsAg. Immunohistochemical staining of the third biopsy for $\mathrm{HBcAg}$ showed that 42 patients (97\%) had no cells staining positive for $\mathrm{HBcAg}$ and only one patient $(2.3 \%)$ had $1 \%$ cells staining positive for $\mathrm{HBcAg}$.

\section{Serum and intrahepatic findings}

The decline in serum HBV DNA, ihHBV DNA, cccDNA as well as HBsAg levels at baseline, one year after treatment and at the time of the third biopsy are shown in Table 2 and Figure 3. Compared with the baseline values, median serum HBV DNA levels decreased by $5.15 \log _{10} \mathrm{IU} / \mathrm{mL}$ and dropped to $<20 \mathrm{IU} / \mathrm{mL}$ by year 1 and remained at similar levels (corresponding to a 5.47 logarithmic reduction) at the time of the third biopsy $(p<0.0001$ compared with baseline levels and $\mathrm{p}=0.02$ comparing between levels at year 1 and at the time of the third biopsy). At the time of the third biopsy, all but one patient had undetectable serum HBV DNA. The remaining patient, on telbivudine treatment, had a serum HBV DNA level of $3.48 \operatorname{logIU} / \mathrm{mL}$, and was changed to tenofovir monotherapy shortly after the liver biopsy.

Median ihHBV DNA levels declined by $1.91 \log$ (corresponding to a $98.77 \%$ reduction from baseline) by year 1 and further declined by the time of the third biopsy (2.81 $\log$ or $99.84 \%$ reduction from baseline; $\mathrm{p}<0.0001$ for all comparisons). Median cccDNA levels declined by $1.03 \log (90.77 \%$ reduction) by year 1 and further declined at the time of the third biopsy (2.94 log or 99.98\% reduction from baseline; $\mathrm{p}<0.0001$ for all comparisons). Twenty one patients $(49 \%)$ had cccDNA levels below detection limit $(<0.005$ copies/cell) in the third biopsy. Twenty-four patients had a peak alanine aminotransferase (ALT) levels of 
$>5$ times the upper limit of normal (ULN). There was a slightly higher proportion of patients with undetectable cccDNA $(15 / 24 ; 63 \%)$ in patients with peak ALT $>5 \times$ ULN than in patients with peak ALT $\leq 5 \times \operatorname{ULN}(6 / 19 ; 32 \% ; \mathrm{p}=0.088)$. Patients with positive $\mathrm{HBeAg}$ at baseline had higher cccDNA levels than HBeAg-negative patients. At the third biopsy, the cccDNA levels were comparable regardless of the baseline HBeAg-status and whether patients had treatment-related HBeAg-seroconversion (Supplementary Tables 3 and 4).

In contrast, median serum HBsAg levels declined by only $0.097 \log (19.97 \%$ reduction) by year $1(\mathrm{p}=0.398$ compared to baseline levels), and there was only a $0.54 \log$ reduction $(71.46 \%$ reduction from baseline) at the time of the third biopsy $(p<0.0001$ compared to both the baseline and year 1 levels). Only one patient had undetectable serum HBsAg at the time of the third biopsy. The decline in HBsAg levels was both slower and to a lesser degree compared to the decline of ihHBV DNA and cccDNA. Also the median serum HBsAg levels was $2.70 \log _{10} \mathrm{IU} / \mathrm{mL}$ (range: -1.30 to 3.85 ) in the 35 patients with $\leq 10 \%$ cells staining positive for HBsAg in the third liver biopsies. This was lower than the median serum HBsAg levels of $3.00 \log _{10} \mathrm{IU} / \mathrm{mL}$ (range: 2.68 to 3.92 ) in the 8 patients with $>10 \%$ cells positive for HBsAg $(\mathrm{p}=0.046)$.

Median HBV pgRNA levels, measured only in RNA extracted from the third liver biopsies, was very low, 0.021 copies/cell (range: 0.003 to 1.53 copies/cell), with 17 patients (40\%) having undetectable pgRNA. Of the 21 patients with undetectable cccDNA in the third biopsy $12(57 \%)$ also had undetectable pgRNA. The remaining nine patients had pgRNA levels ranging from 0.0074 to 0.44 copies/cell. Of the 17 patients with undetectable pgRNA in the third biopsy, $12(71 \%)$ also had undetectable cccDNA. The remaining five patients had cccDNA levels ranging from 0.005 to 0.078 copies/cell.

In the patients with undetectable cccDNA and/or undetectable pgRNA levels in the third biopsy, which can be interpreted as reflecting very little or no viral replication activity, 
there were still high levels of HBsAg in the serum. The levels of serum HBsAg in the patients with undetectable cccDNA and/or pgRNA did not differ from the patients with detectable cccDNA and/or pgRNA levels (Table 3). This suggests that by the time of the third liver biopsies, the serum HBsAg levels were independent of viral replication. This is further shown by the correlation between cccDNA levels and serum HBsAg levels at baseline, year 1 and at the time of the third biopsies (Figure 4). At baseline, though the scatter of HBsAg levels was large, there was still a significant correlation between serum HBsAg levels and cccDNA levels $(\mathrm{p}=0.037, \mathrm{r}=0.319$ due to the large scatter). This correlation was lost at year 1 and at the time of the third biopsy ( $\mathrm{p}=0.096$ and 0.209 respectively). This suggests that before treatment, serum HBsAg levels might partly reflect viral replication. But as viral replication became suppressed through reverse transcription inhibition (year 1) and then through depletion of cccDNA (by the time of the third biopsy), serum HBsAg continued to be produced despite low or even no viral replication. 


\section{DISCUSSION}

cccDNA, the viral mini-chromosome template for HBV RNA transcription, is supposed to be resistant to treatment with nucleos(t)ide analogues (reverse transcriptase inhibitors), and is replenished and amplified from newly formed cytoplasmic HBV rcDNA. Clearance of cccDNA has been defined as a "cure" for chronic hepatitis B [6]. The current study is the first study to document that long-term (more than 6 years) nucleos(t)ide analogue treatment could profoundly reduce the amount of cccDNA from the median baseline level of 7.28 copies/cell to 0.57 copies/cell (90.77\% reduction) after 1 year, and to 0.005 copies/cell (99.89\% reduction from baseline) after a median treatment duration of 126 months. The rapid reduction in the first year of treatment has been previously reported in other studies [11-14], and it may reflect the decline in cccDNA replenishment and amplification with effective inhibition of reverse transcriptase activity. The further reduction with longer periods of treatment may be attributable to natural cell death and cell division of the hepatocytes as has been postulated by Mason et al [8], so that $49 \%$ of patients had cccDNA levels below the detection limit by the time of the third biopsy. The finding that patients with higher peak ALT levels tended to have a higher chance of undetectable cccDNA also supports the postulation that cccDNA reduction is related to increased cell turnover.

HBV pgRNA levels were also very low, with $40 \%$ of patients having HBV pgRNA levels below the detection limit at the time of the third biopsy. However there were patients who had cccDNA levels below detection limit while having detectable pgRNA, or vice versa. This indicates that having cccDNA or pgRNA levels below detection limits may not signify complete "clearance" of these entities. This is similar to the situation of "HBsAg seroclearance", where HBsAg can still be detected in a substantial proportion of patients with more sensitive assays [22], and where severe, and even fatal, reactivations can occur with potent immune suppressors like rituximab [23]. At the time of the third biopsy, ihHBV DNA 
was still detectable in all patients, but was reduced by $99.84 \%$ to a low median level of 0.35 copies/cell. This low level of ihHBV DNA could be attributed to the presence of integrated HBV DNA, which was measured as a part of ihHBV DNA by our assay. The marked reduction of ihHBV DNA together with cccDNA and pgRNA suggest that with long-term nucleos(t)ide analogue treatment, the capacity for viral replication could be suppressed to an extremely low level.

Consistent with other studies [11,24-26], the decline in serum HBsAg levels was much slower and more variable than the decline in cccDNA and ihHBV DNA. Two findings suggest that under long-term nucleos(t)ide analogue treatment, HBsAg continued to be produced independent of viral replication. First, serum HBsAg levels at the time of the third liver biopsies, though lower than at baseline and after one year of treatment, were the same irrespective of whether the patients had detectable or undetectable cccDNA or HBV pgRNA (Table 3). Second, there was a positive correlation between HBsAg levels and cccDNA levels at baseline $(\mathrm{p}=0.037)$. This correlation became only a trend by year $1(\mathrm{p}=0.096)$ and was completely lost by the time of the third biopsies $(\mathrm{p}=0.209)$ (Figure 4). It has been suggested that HBsAg can be produced either from replication-inactive but transcription-active cccDNA or from integrated HBV DNA [9,25]. As proposed by Chevaliez et al [25], we postulate that the relatively slow decline of HBsAg levels is due to the expression of HBsAg from integrated HBV DNA. Chevaliez et al calculated from their study that the median year to "clear" HBsAg was 52.2 years [25]. Histologic findings in the third biopsies revealed that more than $80 \%$ of patients had $\leq 10 \%$ cells staining positive for HBsAg. This finding is in marked contrast to that in untreated patients, in whom there is often abundant hepatocyte cytoplasmic HBsAg, even in the non-replicative phase of infection [27]. The reason for the discrepancies between the intrahepatic and serum HBsAg expressions is not known. But the immunohistochemical detection of HBsAg in histology sections is much less sensitive than 
serum HBsAg assays. In addition, circulating HBsAg may have a longer half-life than intrahepatic HBsAg.

Since $\mathrm{HBeAg}$ seroconversion is often associated with post-conversion reactivation and development of complications of cirrhosis and HCC [28,29], the "ideal" endpoint of treatment at present is deemed to be HBsAg seroclearance [30]. However HBsAg seroclearance is only achievable in 10 to $12 \%$ of patients with current treatment agents. If HBsAg particles are produced in the host hepatocytes even when there is no active viral replication, and the findings of the present study supported this view, then $\mathrm{HBsAg}$ seroclearance may never be achievable in the majority of patients. There have been only very few studies on the reduction of cccDNA with long-term treatment $[31,32]$. Whether it is possible to completely eradicate cccDNA in all patients with longer therapy is uncertain. While there were discrepancies between different studies in the magnitude of cccDNA reduction upon long-term treatment $[31,32]$, our present study showed that cccDNA was depleted after more than 6 years of treatment, with $49 \%$ of patients having cccDNA levels below the assay detection limit. To establish cccDNA depletion as a potential endpoint of treatment, further studies are required to determine whether cccDNA depletion is sustainable after cessation of treatment as well as associated with better long-term outcome for the patients.

Our study is the only study to date to quantitate the changes of ihHBV DNA and cccDNA in human subjects with more than 6 years continuous viral suppression with nucleos(t)ide analogue treatment. It documented, for the first time, that both ihHBV DNA and cccDNA could be markedly reduced with such treatment. It disproves the standard concept that cccDNA is "resistant" to nucleos(t)ide analogue therapy. Furthermore, our study also gave evidence that HBsAg could still be produced despite absence of viral replication as indicated by undetectable cccDNA and pgRNA. Besides HBsAg, our group and others have 
demonstrated the use of other serum markers such as serum HBV RNA [33] or hepatitis B core-related antigen (HBcrAg) [34-36] for the monitoring of HBV activities. Further studies of HBcrAg levels will be performed in our patients to determine whether there is any correlation between HBcrAg and cccDNA levels.

One of the limitations of the present study is the limited (three) time points and the relatively small number of patients for the estimation of the cccDNA and ihHBV DNA levels and the lack of baseline and year 1 samples for immunohistochemical detection of HBsAg and $\mathrm{HBcAg}$. Secondly, a control arm of untreated HBeAg-positive patients was not available to study the effect of $\mathrm{HBeAg}$ seroconversion on cccDNA reduction. Therefore it is difficult to discern to what extent cccDNA reduction was related to HBeAg seroconversion. However, the cccDNA levels at the third biopsy did not correlate with the baseline HBeAg-status nor the occurrence of HBeAg-seroconversion (Supplementary Tables 3 and 4), indicating that the antiviral treatment may play a more important role in cccDNA reduction. Thirdly, there might be sampling errors with liver biopsies.

At present, there are no commercial, standardized assays for the detection of intrahepatic HBV DNA and RNA. However the ihHBV DNA, cccDNA and pgRNA assays used in the present study are based on widely published and accepted methodology $[12,18,19]$. We have adopted the commonly used "over-gap" PCR as well as the use of plasmid-safe DNase for the quantitative detection of cccDNA [12]. In this "over-gap" PCR, a small amount of non-specific amplification of rcDNA may be present, due to the annealing of partial PCR products during amplification. To overcome this problem, plasmid-safe DNase was used to eliminate most of the non-circular DNA, including rcDNA, chromosomal DNA and integrated HBV DNA. Although the activity of plasmid-safe DNase on the portion of rcDNA molecules that have a nearly complete plus-strand is limited [6], our data showed that the non-specific amplification of rcDNA accounts for only less than $0.01 \%$ of the HBV DNA 
population (Supplementary Table 1). Moreover, the limitations of the cccDNA assay mentioned above would only result in false positive values, and therefore not affect the low or undetectable values of this study. In the current study, the cccDNA assay did not detect cccDNA in $49 \%$ of patients at the time of the third biopsy, even allowing for potential false positive results. For future studies, assays with improved sensitivity, as well as assay which can distinguish between integrated and episomal HBV DNA, are required to more accurately measure the low level of intrahepatic HBV DNA in patients under long-term viral suppression.

In conclusion, continuous HBV suppression with long-term nucleos(t)ide analogue treatment progressively reduced ihHBV DNA and cccDNA by over $99 \%$, whereas serum HBsAg levels were reduced by $71 \%$. HBV pgRNA was also below detection limit in $40 \%$ of patients. HBsAg seroclearance may not be achievable in the majority of patients with the currently available therapeutic agents. Whether cccDNA reduction or depletion is sustainable and associated with better outcome remain to be determined. 


\section{FIGURE LEGENDS}

Figure 1. Patient allocation. Flow chart showing the selection process of the 43 patients participating in the study from the 129 patients with biopsies at baseline and after one year of treatment.

Figure 2. Summary of the histologic findings. A. The Knodell scores of the 43 patients at baseline, one year after treatment and at the third biopsy. B. The Ishak scores of the 43 patients at baseline, one year after treatment and at the third liver biopsy.

Figure 3. Effect of treatment on serum and intrahepatic HBV DNA and hepatitis B surface antigen levels. The median levels (with ranges) of serum HBV DNA, total intrahepatic DNA (ihHBV DNA), covalently closed circular DNA (cccDNA) and serum hepatitis B surface antigen (HBsAg) at baseline, after one year of treatment and at the time of the third liver biopsy.

Figure 4. Correlation between serum hepatitis B surface antigen and covalently closed circular DNA levels. The correlation between serum HBsAg levels and covalently closed circular DNA (cccDNA) levels at baseline, after one year of treatment and at the time of the third liver biopsy. 


\section{ACKNOWLEDGEMENTS}

This work was supported by The Lichi Charitable Foundation Limited. We would like to thank all patients who participated in this study. 


\section{REFERENCES}

[1] World Health Organization fact sheet. Hepatitis B. 2015 [cited 13 January, 2016]; Available from: http://www.who.int/mediacentre/factsheets/fs204/en/

[2] Chang TT, Liaw YF, Wu SS, Schiff E, Han KH, Lai CL, et al. Long-term entecavir therapy results in the reversal of fibrosis/cirrhosis and continued histological improvement in patients with chronic hepatitis B. Hepatology 2010;52:886-893.

[3] Marcellin P, Gane E, Buti M, Afdhal N, Sievert W, Jacobson IM, et al. Regression of cirrhosis during treatment with tenofovir disoproxil fumarate for chronic hepatitis B: a 5-year open-label follow-up study. Lancet 2013;381:468-475.

[4] Lai CL, Yuen MF. Prevention of hepatitis B virus-related hepatocellular carcinoma with antiviral therapy. Hepatology 2013;57:399-408.

[5] Addison WR, Walters KA, Wong WW, Wilson JS, Madej D, Jewell LD, et al. Halflife of the duck hepatitis B virus covalently closed circular DNA pool in vivo following inhibition of viral replication. J Virol 2002;76:6356-6363.

[6] Nassal M. HBV cccDNA: viral persistence reservoir and key obstacle for a cure of chronic hepatitis B. Gut 2015;64:1972-1984.

[7] Yang HC, Kao JH. Persistence of hepatitis B virus covalently closed circular DNA in hepatocytes: molecular mechanisms and clinical significance. Emerg Microbes Infect 2014;3:e64.

[8] Mason WS, Cullen J, Moraleda G, Saputelli J, Aldrich CE, Miller DS, et al. Lamivudine therapy of WHV-infected woodchucks. Virology 1998;245:18-32.

[9] Summers J, Mason WS. Residual integrated viral DNA after hepadnavirus clearance by nucleoside analog therapy. Proc Natl Acad Sci U S A 2004;101:638-640. 
[10] Wong DK, Yuen MF, Ngai VW, Fung J, Lai CL. One-year entecavir or lamivudine therapy results in reduction of hepatitis B virus intrahepatic covalently closed circular DNA levels. Antivir Ther 2006;11:909-916.

[11] Wong DK, Seto WK, Fung J, Ip P, Huang FY, Lai CL, et al. Reduction of hepatitis B surface antigen and covalently closed circular DNA by nucleos(t)ide analogues of different potency. Clin Gastroenterol Hepatol 2013;11:1004-1010 e1001.

[12] Werle-Lapostolle B, Bowden S, Locarnini S, Wursthorn K, Petersen J, Lau G, et al. Persistence of cccDNA during the natural history of chronic hepatitis B and decline during adefovir dipivoxil therapy. Gastroenterology 2004;126:1750-1758.

[13] Bowden S, Locarnini S, Chang TT, Chao YC, Han KH, Gish RG, et al. Covalently closed-circular hepatitis B virus DNA reduction with entecavir or lamivudine. World J Gastroenterol 2015;21:4644-4651.

[14] Lu HY, Zhuang LW, Yu YY, Si CW. Virological response to antiviral therapy at week 12 indicates a great reduction of intrahepatic hepatitis B virus DNA and cccDNA in HBeAg-positive chronic hepatitis B patients. J Viral Hepat 2010;17 Suppl 1:59-65.

[15] Chang TT, Gish RG, de Man R, Gadano A, Sollano J, Chao YC, et al. A comparison of entecavir and lamivudine for HBeAg-positive chronic hepatitis B. N Engl J Med 2006;354:1001-1010.

[16] Lai CL, Shouval D, Lok AS, Chang TT, Cheinquer H, Goodman Z, et al. Entecavir versus lamivudine for patients with $\mathrm{HBeAg-negative} \mathrm{chronic} \mathrm{hepatitis} \mathrm{B.} \mathrm{N} \mathrm{Engl} \mathrm{J} \mathrm{Med}$ 2006;354:1011-1020.

[17] Lai CL, Gane E, Liaw YF, Hsu CW, Thongsawat S, Wang Y, et al. Telbivudine versus lamivudine in patients with chronic hepatitis B. N Engl J Med 2007;357:2576-2588. 
[18] Wong DK, Huang FY, Lai CL, Poon RT, Seto WK, Fung J, et al. Occult hepatitis B infection and HBV replicative activity in patients with cryptogenic cause of hepatocellular carcinoma. Hepatology 2011;54:829-836.

[19] Laras A, Koskinas J, Dimou E, Kostamena A, Hadziyannis SJ. Intrahepatic levels and replicative activity of covalently closed circular hepatitis B virus DNA in chronically infected patients. Hepatology 2006;44:694-702.

[20] Ishak K, Baptista A, Bianchi L, Callea F, De Groote J, Gudat F, et al. Histological grading and staging of chronic hepatitis. J Hepatol 1995;22:696-699.

[21] Kleiner DE, Brunt EM, Van Natta M, Behling C, Contos MJ, Cummings OW, et al. Design and validation of a histological scoring system for nonalcoholic fatty liver disease. Hepatology 2005;41:1313-1321.

[22] Seto WK, Tanaka Y, Wong DK, Lai CL, Shinkai N, Yuen JC, et al. Evidence of serologic activity in chronic hepatitis B after surface antigen (HBsAg) seroclearance documented by conventional HBsAg assay. Hepatol Int 2012;7:98-105.

[23] Lai CL, Yuen MF. Management of chronic hepatitis B in patients from special populations. Cold Spring Harb Perspect Med 2015;5.

[24] Manesis EK, Hadziyannis ES, Angelopoulou OP, Hadziyannis SJ. Prediction of treatment-related $\mathrm{HBsAg}$ loss in $\mathrm{HBeAG}-$ negative chronic hepatitis B: a clue from serum HBsAg levels. Antivir Ther 2007;12:73-82.

[25] Chevaliez S, Hezode C, Bahrami S, Grare M, Pawlotsky JM. Long-term hepatitis B surface antigen (HBsAg) kinetics during nucleoside/nucleotide analogue therapy: finite treatment duration unlikely. J Hepatol 2013;58:676-683.

[26] Brunetto MR, Moriconi F, Bonino F, Lau GK, Farci P, Yurdaydin C, et al. Hepatitis B virus surface antigen levels: a guide to sustained response to peginterferon alfa- $2 \mathrm{a}$ in $\mathrm{HBeAg}$ negative chronic hepatitis B. Hepatology 2009;49:1141-1150. 
[27] Wu PC, Lau JY, Lau TK, Lau SK, Lai CL. Relationship between intrahepatic expression of hepatitis B viral antigens and histology in Chinese patients with chronic hepatitis B virus infection. Am J Clin Pathol 1993;100:648-653.

[28] Lai CL, Yuen MF. Chronic hepatitis B--new goals, new treatment. N Engl J Med 2008;359:2488-2491.

[29] Fung J, Lai CL, Tanaka Y, Mizokami M, Yuen J, Wong DK, et al. The duration of lamivudine therapy for chronic hepatitis B: cessation vs. continuation of treatment after HBeAg seroconversion. Am J Gastroenterol 2009;104:1940-1946.

[30] European Association For The Study Of The Liver. EASL clinical practice guidelines: Management of chronic hepatitis B virus infection. J Hepatol 2012;57:167-185.

[31] Manesis EK, Papatheodoridis GV, Tiniakos DG, Hadziyannis ES, Agelopoulou OP, Syminelaki T, et al. Hepatitis B surface antigen: Relation to hepatitis B replication parameters in HBeAg-negative chronic hepatitis B. J Hepatol 2011;55:61-68.

[32] Lacombe K, Boyd A, Lavocat F, Pichoud C, Gozlan J, Miailhes P, et al. High incidence of treatment-induced and vaccine-escape hepatitis B virus mutants among human immunodeficiency virus/hepatitis B-infected patients. Hepatology 2013;58:912-922.

[33] van Bommel F, Bartens A, Mysickova A, Hofmann J, Kruger DH, Berg T, et al. Serum hepatitis B virus RNA levels as an early predictor of hepatitis B envelope antigen seroconversion during treatment with polymerase inhibitors. Hepatology 2015;61:66-76.

[34] Wong DK, Tanaka Y, Lai CL, Mizokami M, Fung J, Yuen MF. Hepatitis B virus core-related antigens as markers for monitoring chronic hepatitis B infection. J Clin Microbiol 2007;45:3942-3947.

[35] Matsuzaki T, Tatsuki I, Otani M, Akiyama M, Ozawa E, Miuma S, et al. Significance of hepatitis B virus core-related antigen and covalently closed circular DNA levels as 
markers of hepatitis B virus re-infection after liver transplantation. J Gastroenterol Hepatol 2013;28:1217-1222.

[36] Honda M, Shirasaki T, Terashima T, Kawaguchi K, Nakamura M, Oishi N, et al. Hepatitis B Virus (HBV) Core-Related Antigen During Nucleos(t)ide Analog Therapy Is Related to Intra-hepatic HBV Replication and Development of Hepatocellular Carcinoma. J Infect Dis 2016;213:1096-1106. 
Table 1. A brief summary of the drug history of the 43 patients included in the study.

\begin{tabular}{|c|c|c|}
\hline $\begin{array}{l}\text { Nucleos }(\mathrm{t}) \text { ide analogue } \\
\text { treatment at baseline }\end{array}$ & $\begin{array}{l}\text { Nucleos(t)ide analogue treatment at } \\
\text { last biopsy }\end{array}$ & $\begin{array}{l}\text { Number of } \\
\text { patients }\end{array}$ \\
\hline \multirow[t]{4}{*}{ Lamivudine } & Adefovir & 2 \\
\hline & Telbivudine & 3 \\
\hline & Entecavir & 7 \\
\hline & Tenofovir & 2 \\
\hline \multirow[t]{2}{*}{ Adefovir } & Telbivudine & 1 \\
\hline & Entecavir & 2 \\
\hline \multirow[t]{4}{*}{ Telbivudine } & Telbivudine & 4 \\
\hline & Entecavir & 4 \\
\hline & Tenofovir & 3 \\
\hline & Lamivudine + Tenofovir & 1 \\
\hline Entecavir & Entecavir & 9 \\
\hline Clevudine & Entecavir & 5 \\
\hline
\end{tabular}


Table 2. HBV DNA, intrahepatic total HBV DNA, cccDNA and serum HBsAg levels at baseline, after 1 year of treatment and at the time of the third biopsies.

\begin{tabular}{|c|c|c|c|}
\hline & Baseline & After 1 year of treatment & At the time of third biopsies \\
\hline Serum HBV DNA, $\log \mathrm{IU} / \mathrm{mL}^{*}$ & $6.92(4.27-11.9)$ & $<1.30(<1.30-10.56)$ & $<1.30(<1.30-3.48)$ \\
\hline Logarithmic reduction $\dagger$ & - & $5.15 \log$ & $5.47 \log$ \\
\hline Percentage reduction $\dagger$ & - & $>99.99 \%$ & $>99.99 \%$ \\
\hline Intrahepatic total HBV DNA, copies/cell* & $285.8(0.494-10,223.6)$ & $3.25(0.038-12,218.2)$ & $0.35(0.037-4.65)$ \\
\hline Logarithmic reduction $\dagger$ & - & $1.91 \log$ & $2.81 \log$ \\
\hline Percentage reduction $\dagger$ & - & $98.77 \%$ & $99.84 \%$ \\
\hline cccDNA, copies/cell* & $7.28(0.018-114.5)$ & $0.57(<0.005-15.1)$ & $<0.005(<0.005-2.13)$ \\
\hline Logarithmic reduction $\dagger$ & - & $1.03 \log$ & $2.94 \log$ \\
\hline Percentage reduction $\dagger$ & - & $98.77 \%$ & $99.89 \%$ \\
\hline Serum HBsAg, $\log \mathrm{IU} / \mathrm{mL}^{*}$ & $3.40(2.07-5.28)$ & $3.28(1.79-5.17)$ & $2.88(-1.30-3.92)$ \\
\hline Logarithmic reduction $\dagger$ & - & $0.097 \log$ & $0.54 \log$ \\
\hline Percentage reduction $\dagger$ & - & $19.97 \%$ & $71.46 \%$ \\
\hline
\end{tabular}

*Values are expressed as median (range); †Median reduction compared with the baseline values 
Table 3. Median serum HBsAg levels in patients with or without detectable cccDNA and pgRNA at the time of the third biopsy

\begin{tabular}{lll}
\hline cccDNA or pgRNA status at the third biopsy & Median serum HBsAg, & p value \\
& logIU/mL (range) & \\
\hline Undetectable cccDNA $(\mathrm{n}=21)$ & $2.88(-1.3-3.58)$ & 0.68 \\
Detectable cccDNA $(\mathrm{n}=22)$ & $2.81(1.55-3.92)$ & \\
& & 0.55 \\
Undetectable pgRNA $(\mathrm{n}=17)$ & $2.88(-1.3-3.85)$ & \\
Detectable pgRNA (n=26) & $2.83(1.55-3.92)$ & \\
Undetectable cccDNA and/or pgRNA (n=26) & $2.81(-1.3-3.85)$ & 0.49 \\
Detectable cccDNA and pgRNA (n=17) & $2.97(1.55-3.92)$ & \\
\end{tabular}


129 patients from 3 previous clinical trials

Entecavir vs. lamivudine: 20 vs. 18

Telbivudine vs. lamivudine: 36 vs. 31

Clevudine vs. adefovir: 16 vs. 8

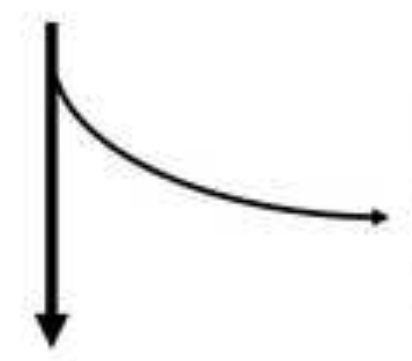

5 patients excluded from study:

with no frozen tissue (at baseline and/or

week 48) for cccDNA assessment

\section{4 patients}

with both baseline and

week 48 biopsy

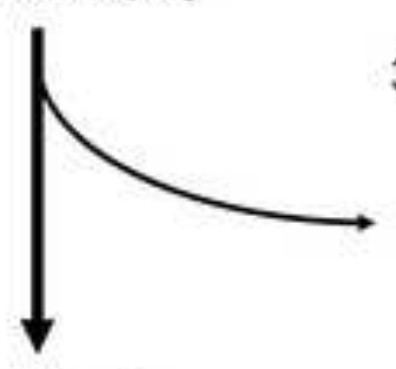

39 patients excluded from study:

5 patients - $4 \mathrm{HCC}$ and 1 colon cancer

17 patients - lost to follow-up

17 patients - discontinued drug for $>6$ months

85 patients

continued to receive

nucleos(t)ide analogues

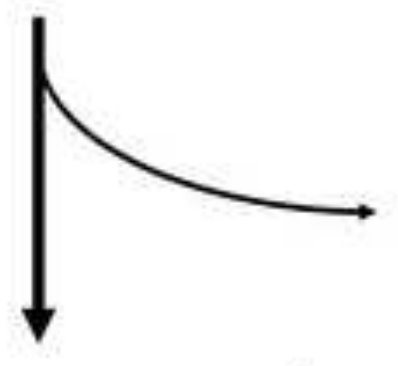

42 patient refused the third biopsy

\section{3 patients* agreed} to third biopsy *one patient, on 0.5 - $1 \mathrm{mg}$ entecavir (according to trial protocol), lost HBsAg after 68 months of treatment but continued to receive entecavir by his own choice up to the time of the third biopsy at 128 months of treatment 
A

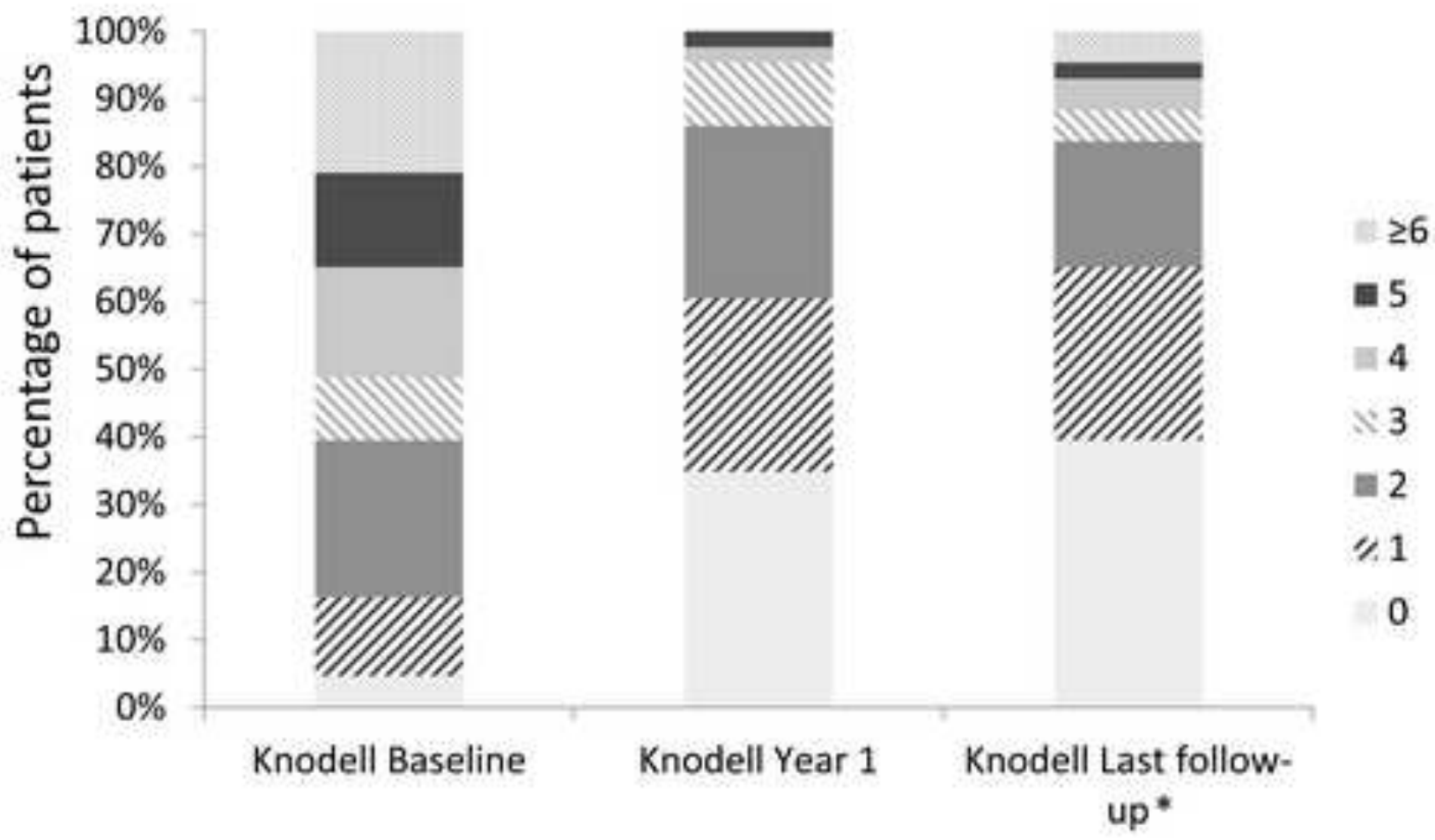

B

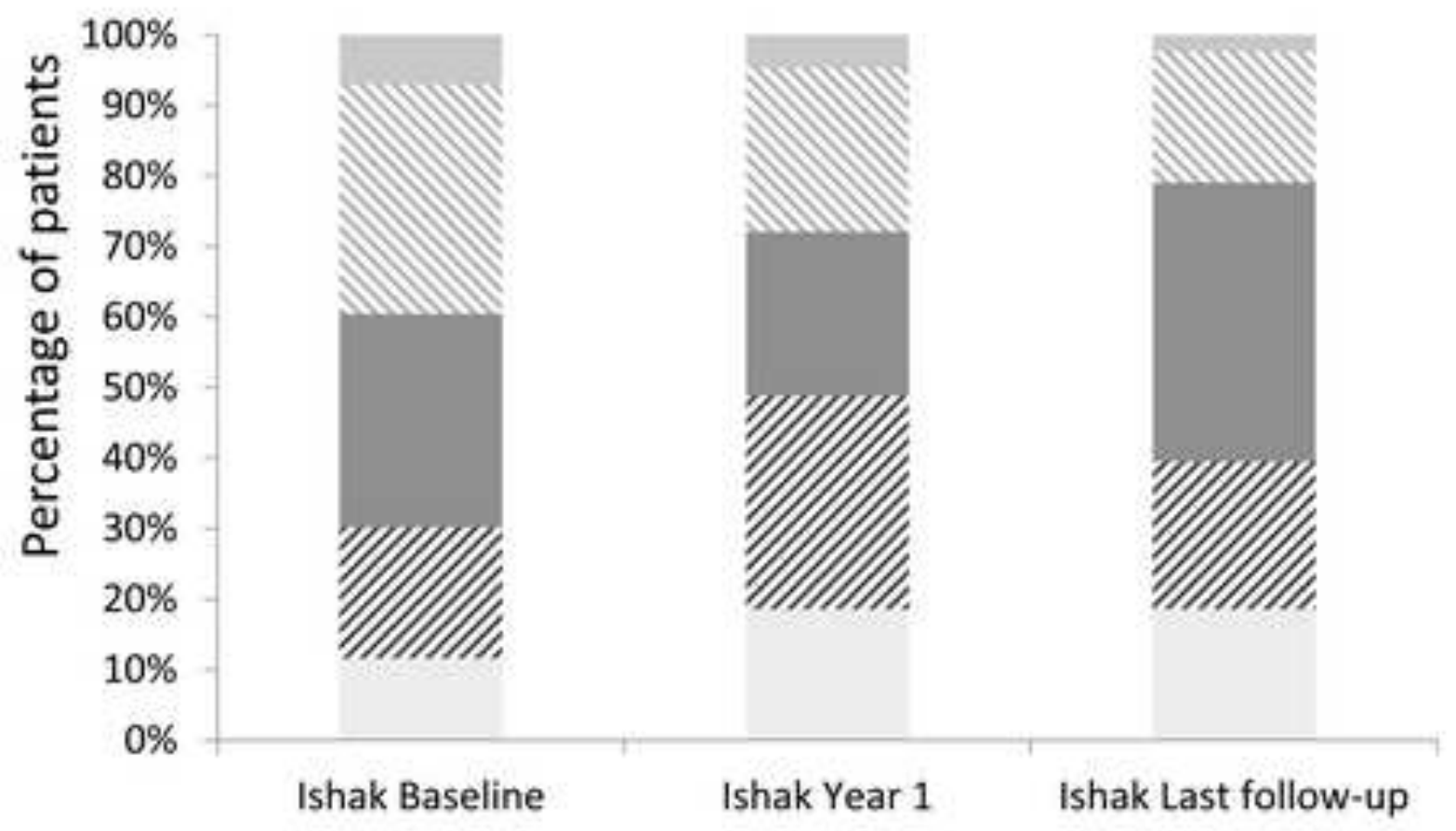

* Three patients showed increase in portal infiltration in the third biopsy; the reason is not known since all had undetectable HBV DNA and no increase in steatosis 


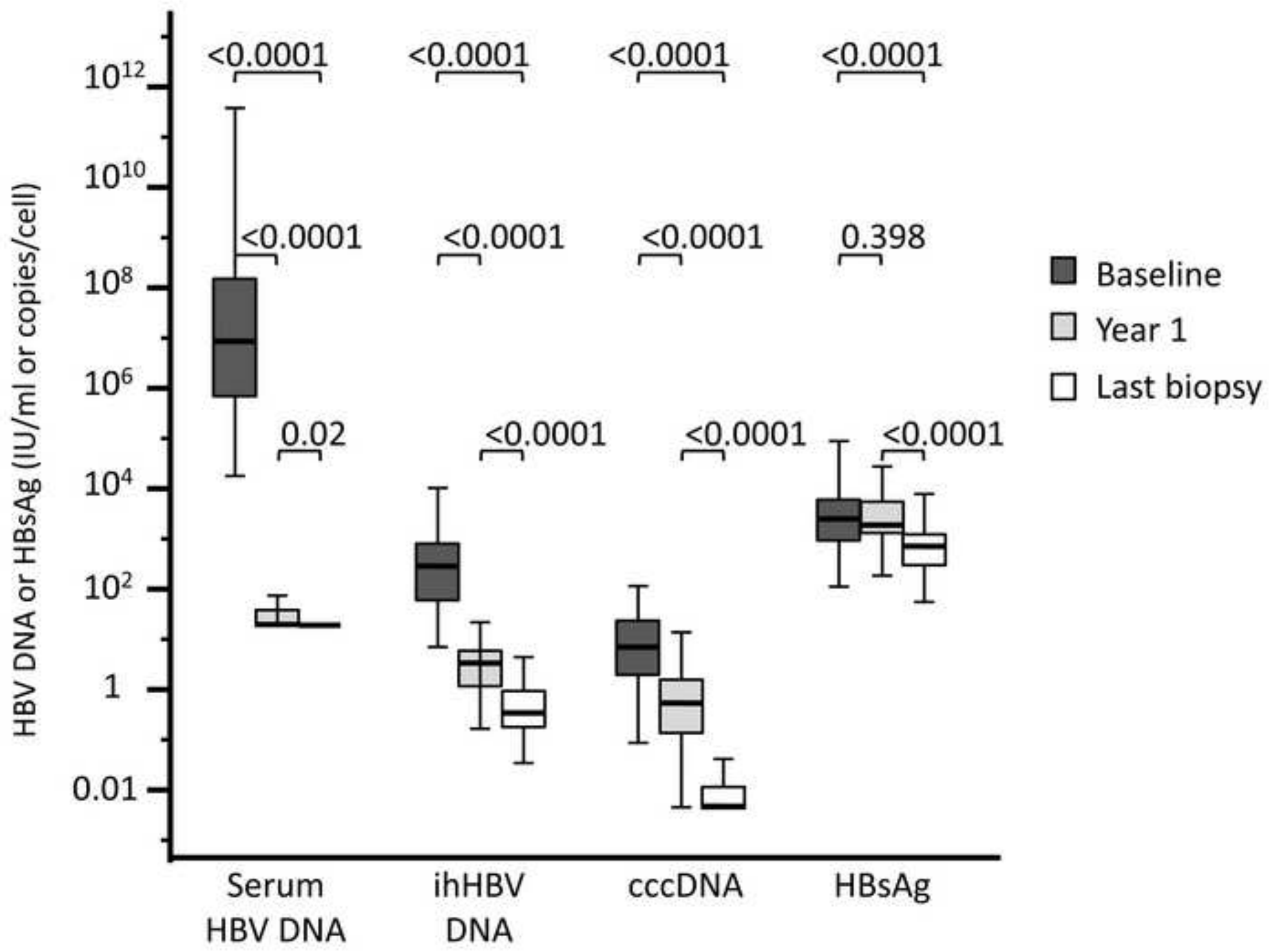


Click here to download high resolution image
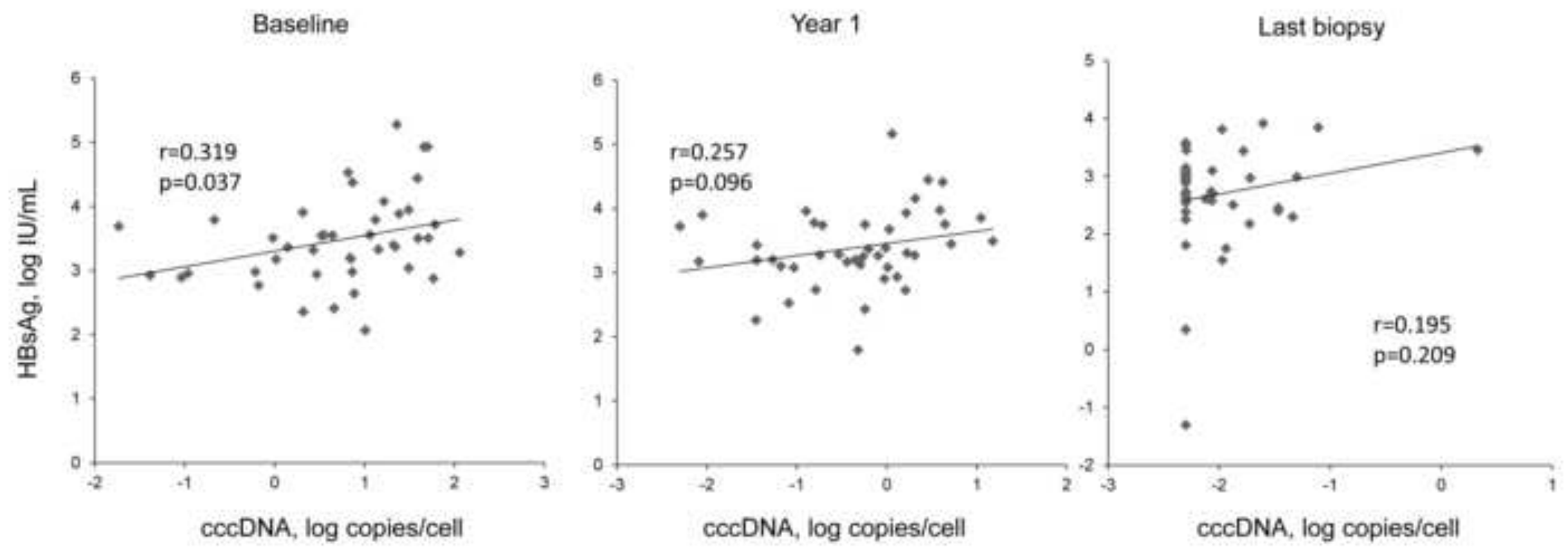
*ICMJE disclosure form
Click here to download ICMJE disclosure form: ICMJE coi_disclosure forms.pdf

*ICMJE disclosure form
Click here to download ICMJE disclosure form: ICMJE coi_disclosure forms.pdf

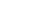

\author{
(
}

(

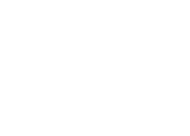
(1) $\sqrt{3}$ (1) (1) (1)

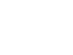
. . . . . . . . . . . . 
43 chronic hepatitis B patients with continuous nucleos(t)ide analogue therapy with 3 liver biopsies

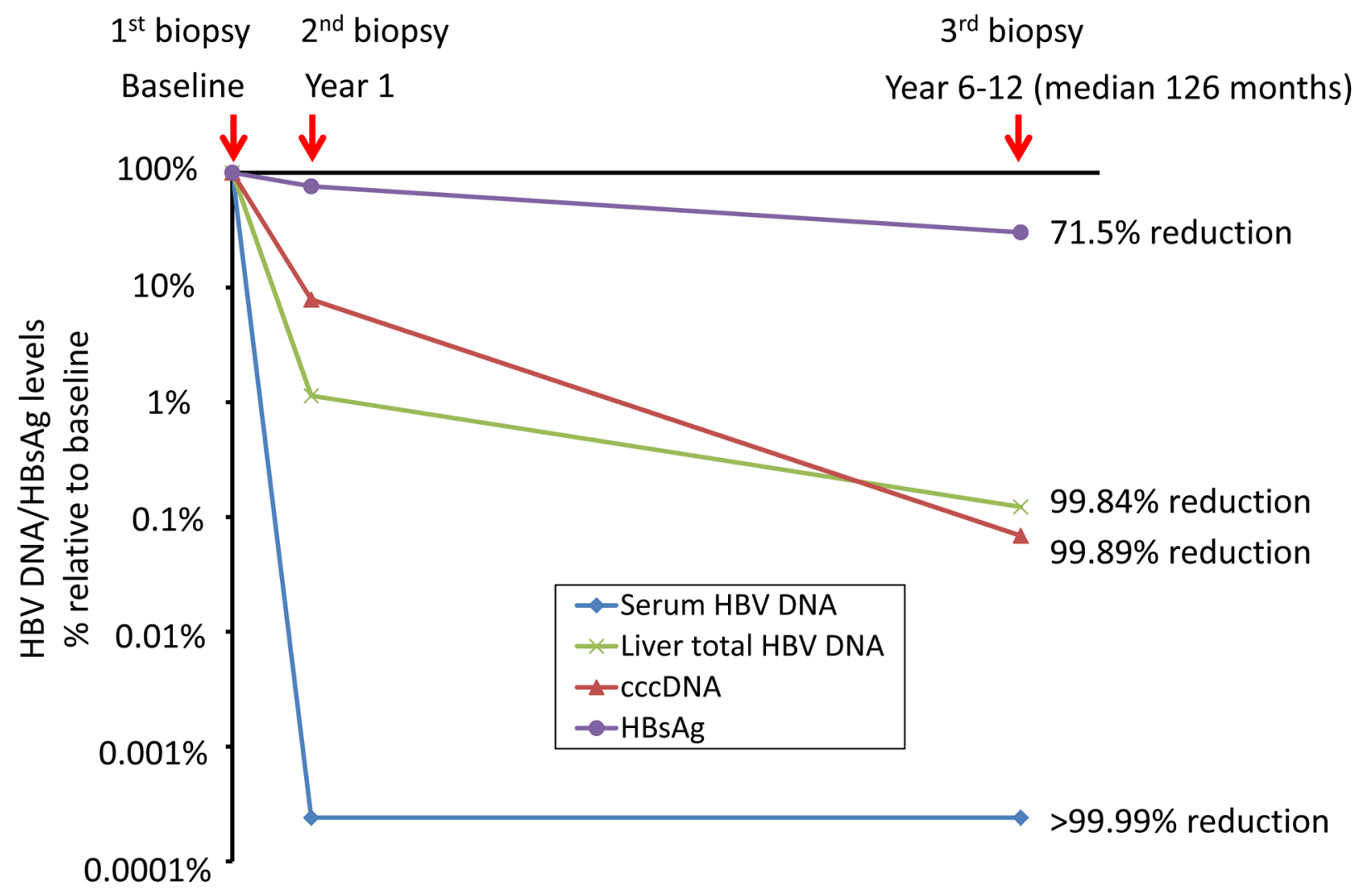

Conclusions: Long-term nucleos(t)ide analogue treatment induced marked depletion of cccDNA in the majority of patients while serum HBsAg levels, though reduced, were detectable in all but one patient. 
Supplementary material
Click here to download Supplementary material: Supplementary information.docx

Supplementary material
Click here to download Supplementary material: Supplementary information.docx

\begin{abstract}
click here to download Supplementary material: Supplementary information.docx
\end{abstract}

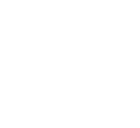

.

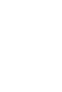

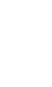

.

.

更

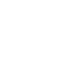

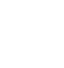

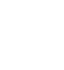

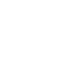

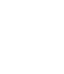

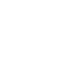

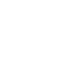

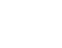

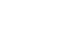

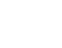

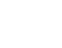

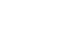

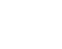

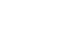

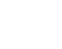

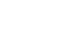

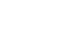

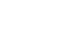

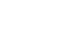

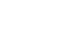

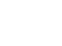

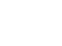

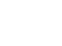

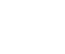

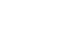

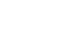

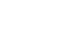

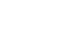

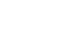

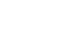

